\title{
5. THE EVALUATION BETWEEN PARTIAL AND IMPARTIAL ATTITUDE
}

\begin{abstract}
Docimology is based on knowledge from the field of psychology and pedagogy. There are several functions of the didactic evaluation, related to their social and personal relevance. The interpretive evaluation involves a degree of subjectivism which, however, can be diminished by experience, patience and permanent self-control. The proposed evaluation methods will be applied simultaneously, with the objectification of the relevance of each one and with maximum sense of responsibility on the part of the evaluator.
\end{abstract}

Key words: assessment, objective, subjective, teaching methods

\section{Introduction}

Insufficiently researched process, didactic evaluation is generally carried out on an intuitive basis or from one's own experiences gained as a student. The first researches in the field were undertaken by the French psychologist Henri Pieron, in the work Etudes docimologiques published in Paris in 1935, where the term docimology also appears (dokime $=$ proof, $\log o s=$ science). Professor Mircea Dan Răducanu included years ago in his courses and a chapter dedicated to this science, the initiative arousing the interest of students from the Iasi Conservatory.

\section{Discussions}

As a science, the docimology is based on researches in the field of general, social and school psychology, correlated with pedagogical principles, starting from establishing the personality of the evaluator and analyzing the problem of evaluation as a multiple elaborated phenomenon (evaluation by different juries or commissions). According to Max Marchand ${ }^{70}$, there are three types of educators, namely the rigid type (which is limited to teaching and is opaque to the other sides of the student's life), the egocentric type (motivated only by personal satisfaction) and the type of pedagogue dedicated entirely to the profession, which is involves in the lives of his disciples in all aspects. The evaluation within the educational process concerns both the social side and that of personal development. Thus, the following functions of evaluation are distinguished:

- The validating social function

- The accumulation of knowledge necessary for a certain type of activity

- The products of the education system

- School orientation, at all levels of education

${ }^{69}$ Lecturer PhD., „George Enescu” National University of Arts from Iaşi, Romania, email: luminita.ciobanu@gmail.com

${ }^{70}$ Max Marchand (1911-1962), French writer and educator. 
- The function of school, social and professional selection, expressed by the hierarchy of didactic results.

\section{Pedagogical functions that refer to both evaluators and evaluators}

Thus, for the students / students, the evaluation has the role of influencing the psychic development, ensures the maintenance of a high level of knowledge as well as their living and has an influence on the volitional side by impregnating a type of systematic work and concrete interests. The evaluation helps the teachers to gain knowledge about the class and / or individual level and to find new methods meant to ensure the progress of the children but also their social insertion. The pedagogical functions specific to the instructive-educational act are following:

1. Finding and appreciating the results

2. Diagnosis - is based on the verification and interpretation of the results

3. Prognostic - new suggestions and guidelines for the evaluated result

4. Selection - classification of students / students - useful product for competitions

5. Certification or recognition of a candidate's level

6. Motivational - stimulates self-esteem, self-awareness and interest

7. Counseling - the orientation or reorientation of children and parents towards another field is realized in case of unsatisfactory results, realizing a balance between desires and capacities.

The structure of the evaluation act comprises 3 stages:

1. Verification - by applying strategies and methods, information is obtained regarding the level of performance at a certain time.

2. Measurement - the results are interpreted by means of certain parameters

3. Scoring - generally it is done as an attribute of the school progress, namely the quantification of the level of knowledge, skills, aptitudes.

According to Jean Piobetta, not every teacher can also be a good examiner - The art of examining involves very different qualities from those required by the art of teaching. You can be an excellent teacher, without being a good examiner and there is no room for annoyance here, as you cannot be angry if you are not a good musician ${ }^{71}$. However, a good teacher (...) can and must be a good examiner; it must, because the objective appreciation of knowledge enters into its obligations as a teacher and educator, and it can become, because the acquisition of this quality depends mainly on information and experience; being unstructured, this quality can be formed by effort of will, patience, self-control, exercise and skill; effort by excellence, to exceed the limits of subjectivity ${ }^{72}$.

The reception of the interpretative act, with the psychological particularities of the auditor, determines the completion of the artistic communication act. Lucian Blaga, in Letters about art ${ }^{73}$, showed that empathic perception is composed of a

\footnotetext{
${ }^{71}$ Piobetta, J.B. - Examens at concours, Paris, P.U.F., 1943, pg 74

${ }^{72}$ Pavelcu, V., Principles of docimology, Didactic and pedagogical edition, Bucharest, 1968, pg. 140

${ }^{73}$ Blaga, L., Letters about art, Ed Meridiane, Buc., 1970
} 
cognitive and an aesthetic side. In the first case, the listener perceives possible states and situations of reality, and in the second case, he experiences the states realized within the artistic approach. These also relate to the degree of complexity of the interpretive act. Thus, the more the artistic stimulation is more complex, the stronger the effect in the receiver - the comprehensibility of the message is directly proportional to the organization of the discourse and conversely proportional to its complexity. . [...] The artistic practice has demonstrated with some evidence that in order to ensure a suitable degree of comprehensibility of the artistic message (interpretive), the degree of complexity must be at a medium level, avoiding the extremes, that is, both the triviality and the excess of originality ${ }^{74}$.

The overall human capacity for assessment and evaluation is extremely different and otherwise it is desirable not to be uniform, but according to the unit of measure specific to each evaluator. In addition to these aspects, we must also bear in mind that one and the same interpretation may be judged differently at different times, or at certain time intervals. Although the ideal of docimology is the total elimination of subjectivity, this is practically impossible as long as we are dealing with the unstable and variable human factor. This could possibly be accomplished by introducing standardized algorithms to be evaluated by a computer, which would make it impossible to capture fine details within the interpretative act.

To remain in the field of human subjectivity, we will recall that there are two types of criteria of subjectivity - the quantitative one (the one by which the evaluating subject refers to a degree of accuracy - clarity, the lack of text errors) and the qualitative one (in which the evaluator is refers to one's own concept of ideal or to traditional models). The individual value scale comprises, according to Prof. M.D. Răducanu, the following elements involved in the evaluation and which make it subjective

1. Degree of musical endowment of the examiner (it is desirable that it be at least equal to that of the examiner if not favorable to the former)

2. The absolute value of the subjective option - its elements belong to the personal appreciation (sound quality, dynamic, tempo, phrasing), they constitute a synthesis in the process of artistic communication, therefore, each interpretation produces a new synthesis of these parameters.

3. The comparative value between the sound ideal and the exposed version - in which there are 3 degrees of (mental) equivalence, between quasi-equivalence and total disjunction - extremely rare case.

4. The ability to decipher the elements of musical perception - it is about separating the act of hearing (sensitive level) from that of the actual listening (complex level).

5. The evaluative experience of the evaluator - this is the only way by which

\footnotetext{
${ }^{74}$ Răducanu, M.D., Docimology of the interpretive act, Ed PIM, Iasi, 2006, pg.13-14
} 
appreciation and rating activity are perfected.

6. The own experience as an instrumentalist - what the evaluator has experienced through research and play, can be appreciated more accurately.

Evaluation is, in fact, a mental action that establishes a value expressed in an abstract quantity that reflects an interpretive performance. The appreciative act is simultaneous or successive with the hearing process, being an immediate consequence of the latter ${ }^{75}$.

The assessment first of all includes the execution itself, in which case the correctness of the musical text, the intonation, the rhythm, the tempo, the motor development are taken into account. The qualitative assessment will evaluate the musical intelligence, the stylistic knowledge, the maturity level of the performer. In the musical interpretation, different methods of evaluating the interpretive act are proposed, namely:

1. General impression method - it is extremely used and generally translates into terms that I like or I care about. Although it seems superfluous, this method actually captures the value of interpretation, distinguishing some general effects, such as manner or spontaneity, platitude, etc.

2. The analytical method - represents the degree of professionalism of the evaluator / them and represents an analysis by decomposing the elements of interpretation into well-defined issues, which are subject to the general subjectivity of the commission or jury. Usually the final evaluation is expressed in the average of the grades, which does not quite reflect the level of interpretation. 3 . The method of determining the density of errors - the mistake can be a simple mismatch of the text with the audited material or it may be something more vague, when determined by the evaluator's personality. It is therefore good for this method to be used in completing the first two evaluation methods.

4. Comparison method - this actually establishes the hierarchy of the values of the audited ones. This type of evaluation has as a weak point the effects of order and halo, due to which the examiner is not constant throughout the candidates hearing.

\section{Conclusions}

In conclusion, we can say that in assessing the instrumental interpretation (execution and actual interpretation), several methods can be used, as described. It is not desirable to apply a single method exclusively, which would significantly narrow the field of reference, but not their simple combination without understanding the significance of each of them. The final result must be characterized by a sense of responsibility on the part of the evaluator.

\footnotetext{
${ }^{75}$ Răducanu, M.D.., op.cit, pg, 31
} 


\section{References}

1. Blaga, L., Letters about art, Editura Meridiane, București, 1970

2. Ciocan, D. (2006) A semiotic theory of musical interpretation, Editura UNMB, București

3. Pavelcu, V., Principles of docimology, Editura Didactică și Pedagogică, București, 1968, pg. 140

4. Piobetta, J.B. - Examens at concours, Paris, P.U.F., 1943, pg 74

5. Răducanu, M. D. (2006) Docimology of the interpretive act, Editura PIM, Iași

6. https://www.verywellmind.com/what-is-the-yerkes-dodson-law-2796027

7. https://en.wikipedia.org/wiki/Hermann_Ebbinghaus 